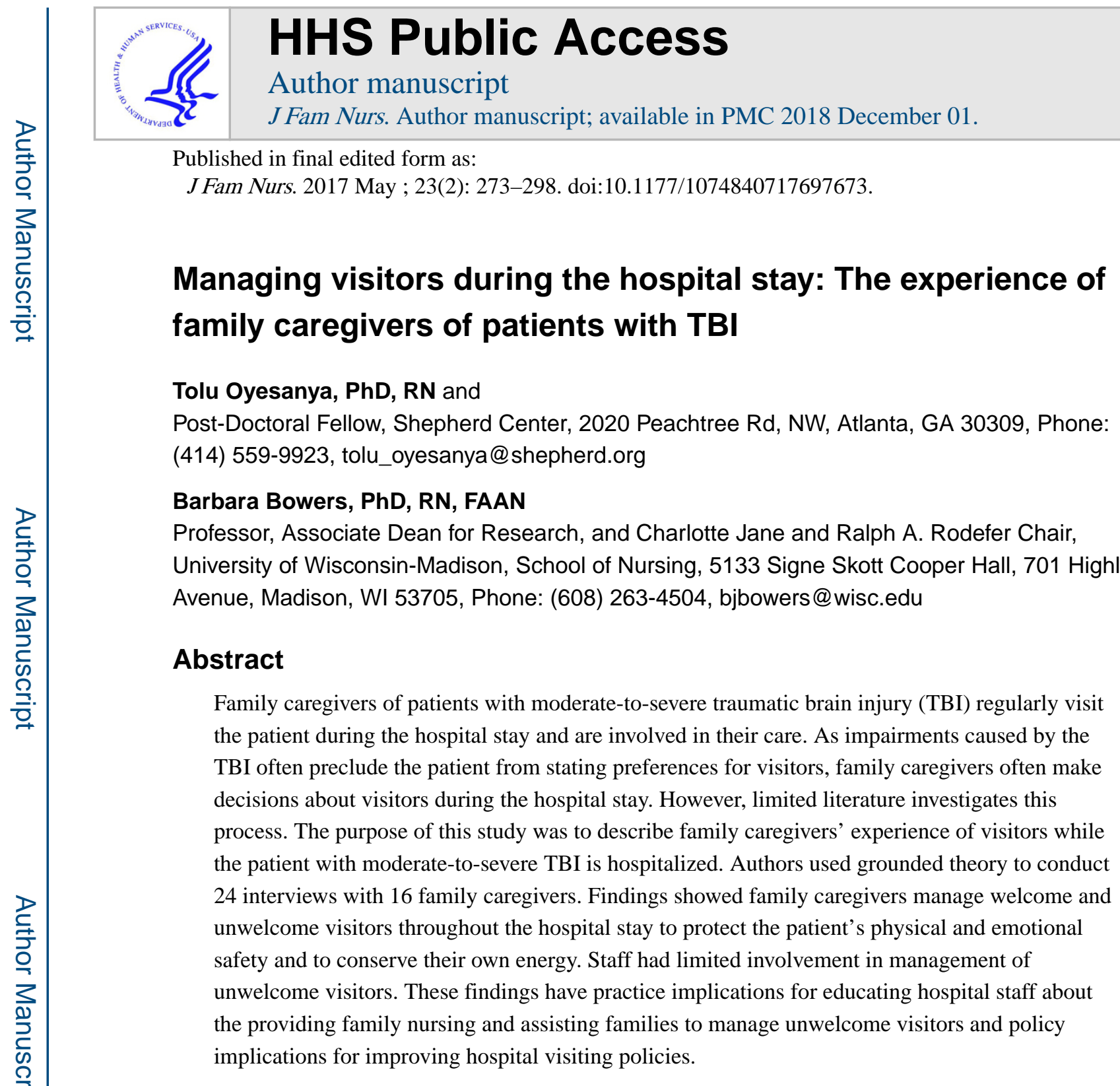

\title{
Keywords
}

traumatic brain injury; patients; family caregivers; visitors

Traumatic brain injury (TBI) can be defined as "a bump, blow or jolt to the head or a penetrating head injury that disrupts the normal function of the brain" (Centers for Disease Control and Prevention, 2014). TBI occurs frequently around the globe, as over 10 million people sustain a TBI each year internationally (Majdan et al., 2016), and over 2.5 million of those injuries occur in the United States alone (Centers for Disease Control and Prevention, 2014). Over 75\% of all TBI cases are mild (Centers for Disease Control and Prevention, 2016), but individuals who sustain a moderate-to-severe TBI often face significant

Address all correspondence to: Tolu Oyesanya, PhD, RN, Post-Doctoral Fellow, Shepherd Center, Crawford Research Institute, 2020 Peachtree Rd, NW, Atlanta, GA 30309; tolu_oyesanya@ shepherd.org.

Conflicts of Interest: The authors have no conflicts of interest to declare. 
immediate and chronic impairments (Corrigan \& Hammond, 2013) that tremendously effect their lives and the lives of their family members.

\section{Consequences of TBI}

Moderate-to-severe TBI causes immediate and long-lasting cognitive-communication, physical, or behavioral impairments that require immediate hospitalization for ongoing treatment and rehabilitation (Kolakowsky-Hayner, Bellon, \& Yang, 2016). Cognitive impairments primarily focus on changes in thinking skills, including: problems with memory, attention, problem solving, and executive function; lack of awareness and insight; delayed processing; and difficulty with new learning (Failla, Juengst, Graham, Arenth, \& Wagner, 2016). Communication impairments refer to difficulty understanding or producing speech in either written or spoken messages (Despins, Turkstra, Struchen, \& Clark, 2016). Physical impairments include loss of consciousness, headaches, seizures, nausea and vomiting, and problems with movement and balance (American Speech-Language-Hearing Association, 2017). Behavioral impairments can include agitation, combativeness, irritability, impulsivity, anxiety, and depression (Failla et al., 2016). The impairments cause by TBI have a significant effect on the life of person with TBI and on their family members, including role reversal, and issues with social relationships, employment, and learning (Togher, McDonald, Tate, Rietdijk, \& Power, 2016). Many of these impairments render the person with TBI unable to make decisions for themselves (Steward et al., 2016).

\section{Family Involvement during the Hospital Stay}

Due to the patient's impairments caused by the TBI, family caregivers are often involved in the hospital care of the patient (Oyesanya \& Bowers, in press). After spending long hours at the hospital, some family caregivers expressed a desire to help staff with patient care, such as assisting with the patient's bath (Oyesanya, 2017). Other family caregivers are involved in the patient's care by sharing information with staff to help them understand the patient better (Nalder, Fleming, Cornwell, \& Foster, 2012). Still others are involved by advocating for the patient and attempting to plan for the patient's future (Gagnon, Lin, \& Stergiou-Kita, 2016). Family caregivers' involvement in the patient's care often occurs while visiting (Oyesanya \& Bowers, in press).

\section{Families' Perceptions of Visitors during the Hospital Stay}

No literature exists on families' perceptions of visitation for patients with moderate-tosevere TBI. The general literature on visitation focuses on other acute health conditions and shows that most family members have preferences about visitors, preferring immediate and extended family members over other visitors (Wu et al., 2015). Research on visitation for other acute health conditions shows that family caregivers attempt to support the patient during the hospital stay through physical presence and comfort (Chapman et al., 2016). Family caregivers' perception that their physical presence is beneficial to the patient increases their desire to be physically present with the patient on regular and frequent basis (Chapman et al., 2016). As impairments caused by moderate-to-severe TBI often preclude the patient from being able to make decisions during the hospital stay (Steward et al., 2016) 
or to state their visiting preferences, family caregivers of these patients often make decisions about visitors on the patient's behalf.

\section{Knowledge Gaps in Visitation Literature}

Despite the plethora of research on general hospital visitation (Chapman et al., 2016; Clay \& Parsh, 2014; Hart, Hardin, Townsend, Ramsey, \& Mahrle-Henson, 2013), gaps in knowledge exist because most literature only focuses on issues such as frequency and duration of visitors, and limited literature is available on patients with TBI. First, much of the literature focuses on visits to the patient while in critical care. However, visitors are present throughout the hospital stay, regardless of the unit or phase of recovery. Second, few studies have taken quality or appropriateness of visiting into account, including the appropriate number, frequency, timing, and types of visits. Third, only two articles are available about visitation concerning patients with cognitive impairments, including patients with moderateto-severe TBI. The available literature on visitation for patients with moderate-to-severe TBI provides limited direction due to inconsistencies in the negative (Turkstra, 2013) and positive (Gorji, Araghiyansc, Jafari, Gorgi, \& Yazdani, 2014) effects of visitors, suggesting the need for additional research.

Fourth, the number, frequency, and duration of visitors are often determined based on patient and staff preferences. However, patients with cognitive impairments, including people who have unconsciousness, amnesia, and limited awareness caused by moderate-to-severe TBI are unable to make decisions (Steward et al., 2016), including decisions about visitors. Thus, family caregivers often make decisions about visitors on the patient's behalf. Yet, no research on this topic could be found, which limits in-depth information that will inform nurses about: 1) how family caregivers make decisions about managing visitors, 2) the work and wellbeing of these family caregivers in this process, and 3) the ability of healthcare providers and researchers to make recommendations on opportunities for collaboration to manage visitors between nurses and family caregivers in this process. Therefore, the purpose of this article is to describe family caregivers' experience of visitors while the patient with moderate-to-severe TBI is hospitalized.

\section{Methods}

\section{Study Design}

We conducted this study using grounded theory to examine the process of managing visitors during the hospital stay for family caregivers of patients with moderate-to-severe TBI (Bowers, 1990; Bowers \& Schatzman, 2009). Our goal was to build a beginning conceptual model describing family caregivers' experience of the hospital stay. Based on symbolic interactionism, grounded theory is particularly well suited for exploring how a participant understands a situation and the actions that flow from that understanding (Bowers, 1990). In addition, the sociological foundation of the method facilitates locating the phenomenon under study within particular social contexts and conditions. This allows the researcher to explore how various conditions influence the participants' understanding and actions (Blumer, 1969). As very little is currently known about the experience of these family 
members, methodologies that are guided by predetermined conceptual models or existent literature would be less appropriate for the task (Creswell, 2014).

After receiving approval from the participating institutional review board, participants were recruited from three inpatient rehabilitation facilities in the United States. Two inpatient rehabilitation facilities were in-hospital rehabilitation units located inside large, academic medical center with 25 beds, and the third was a free-standing rehabilitation facility with 50 beds. No rehabilitation facility involved in this research study specialized in care of patients with TBI. Patient-specific inclusion criteria included: 1) age 18 years or older; 2) diagnosed with moderate-to-severe TBI; 3) Glasgow Coma Scale score between 3-12 on admission to inpatient rehabilitation; and 4) currently undergoing inpatient rehabilitation. Each family caregiver was eligible to participate if they: 1) were age 18 years or older; 2) spoke English fluently, by self-report; and 3) identified as the anticipated primary family caregiver after discharge. We defined anticipated primary family caregiver as the person who planned to be most involved in the patient's care after hospital discharge. Other family members who were highly involved in the patient's hospital stay but were not the primary family caregiver also participated. These other family members often became aware of the study if they were present while the nurse manager was recruiting the primary family caregiver and volunteered to participate. When this occurred, the primary family caregiver encouraged the other family member to participate.

A different nurse manager at each of the three recruitment sites approached all primary family caregivers to determine interest in participation. To ensure they used a consistent approach, each nurse manager was given a script to use in directing their conversations with family caregivers for the recruitment process. When the family caregiver expressed interest in participating, the nurse manager distributed a study information sheet with the first author's contact information. The first author gave all interested participants detailed information about the study, including the study purpose and necessary study activities. After reading the informed consent and asking any questions, all participants signed the informed consent prior to the first interview.

\section{Study Participants}

A total of 15 patients were eligible to participate and none were identified as index cases. When approaching the family caregivers of eligible patients, two declined to participate. The final sample included 16 family caregivers associated with 13 patients with TBI. All family caregivers were white, most were women $(n=14)$, and most self-identified as the primary family caregiver after discharge $(n=14)$. The average age of primary family caregivers was 55 years (range $=22-76$ ). Biological relationships of primary family caregivers included: parents $(n=5)$; spouses $(n=7)$; and other $(n=1)$ (i.e., child). Biological relationships of other family members who participated included: other $(n=3)$ (i.e., grandparent, sibling, and cousin). Patients were all white and were mostly men $(n=11)$. Causes of injury included falls $(n=8)$, motor vehicle accidents $(n=3)$, and other $(n=2$; e.g., gunshot wound). All patients were unconscious upon arrival to the hospital and were in a coma in the ICU for an extended period of time (ranging from 1-12 days). The patients' average age was 47 years (range=1979) and average length of hospital stay at the time of the first interview with the family 
caregiver was 26.30 days (range=8-40). Finally, patients' average length of stay at the inpatient rehabilitation facility was 17.09 days (range=5-33).

\section{Data Collection}

Interviews with family caregivers occurred between February 2015 and July 2016. The first author conducted all 24 semi-structured interviews with family caregivers. Each family caregiver was interviewed one $(n=16)$ or two times $(n=8)$; second interviews were used to add depth to the conceptual model. The first eight family caregivers were asked to do a second interview as the initial interviews were pertinent in providing direction for development of the conceptual model. During second interviews, the first author asked follow-up questions developed based on information provided by the participant during the first interview. These follow-up questions allowed the authors to further understanding of the participants' experience. Questions during the second interview included asking for additional examples that illustrated their experience and for feedback on the conceptual model.

Interviews averaged 68 minutes (range 48-150). The first interview occurred 7 days after admission to inpatient rehabilitation. The second was held 48-72 hours before discharge, which was 4-7 days after the first interview. Interviews were conducted in a private conference room at the inpatient rehabilitation facility and were audio recorded and transcribed verbatim. All data were kept on a password-protected computer that was connected to a secure server, and the computer was located in a locked research office.

Authors also used theoretical sampling, which can be achieved through selection of subsequent participants or by revision of interview questions to explore directions indicated by ongoing analysis (Strauss \& Corbin, 1998). Due to the limiting nature of our recruitment process (i.e., inability to select for characteristics of the patients' and family caregivers' circumstances under which the TBI was sustained), theoretical sampling was pursued by revising interview questions to follow the ongoing analysis. For example, during the first four interviews, family caregivers were asked, "Can you tell me about what things have been like for you while your family member has been in the hospital?" allowing family caregivers to determine the direction of the interview. Although family caregivers were interviewed while the patient was undergoing inpatient rehabilitation, interview questions asked family caregivers to reflect on their full hospital experience (from admission to ICU up until 48-72 before hospital discharge). Most family caregivers spontaneously identified concerns about visitors throughout the hospital stay, specifically their influence on the patient. To add depth to the conceptual model, subsequent participants were asked, "What is your experience with visitors while your loved one has been hospitalized?" Follow-up interview questions became more focused to identify all dimensions, conditions, and interactions among categories.

Although questions evolved throughout the study, the authors used a topic or interview guide with each participant.

\section{Data Analysis}

The authors followed tenets of grounded theory to conduct data collection and analysis, specifically procedures outlined by Strauss and Corbin (1998) and Charmaz (2014), which 
directs the researcher to begin data analysis early (i.e., immediately after the first interview) and to conduct data collection and analysis simultaneously (Strauss \& Corbin, 1998) with a research team (Charmaz, 2014). The research team consisted of two professors of nursing who are grounded theory experts with over 40 combined years of grounded theory expertise, and five nursing doctoral students well-versed in grounded theory methodology.

To reduce bias, interview questions began with a broad focus on the experience of the hospital stay instead of asking leading questions (Strauss \& Corbin, 1998). However, participants immediately began discussing management of visitors to protect the patient's safety without prompting. As grounded theory directs the research to follow the direction of the participants' perspectives (Strauss \& Corbin, 1998), we revised interview questions to gain an in-depth understanding of the participants' experience of managing visitors. For instance, during an interview, a family caregiver shared, "we didn't want a parade of people going and coming through her hospital room because it wasn't safe" [Caregiver \#3]. This quote indicated the family caregiver had concerns about visitors and how they influenced the safety of the patient. In a subsequent interview with the same family caregiver, the first author asked follow-up interview questions focusing on visitors, including:

1. You said a parade of people coming to see your daughter would be unsafe. Could you please tell me why this would be unsafe?

2. What could've happened if the wrong people came to see your daughter?; and

3. How do you choose who should come see your daughter and who shouldn't?"

These questions elicited new data about the process of managing visitors, allowing the authors to obtain detailed data that was related to the core category, managing visitors.

Detailed coding and data analysis procedures.-Following the tenets of grounded theory, our data analysis process included open, axial, and selective coding (Charmaz, 2014), each described in detail below. Analysis of our data began with open coding, consisting of line-by-line analysis of each transcript (Strauss \& Corbin, 1998). For example, a family caregiver shared:

"When people came unannounced, we told them that we would contact people when she was actually conscious, and when it would actually mean something to her because then it would be familiar faces. But what's the point of sitting there staring at her, unconscious in a bed with a ventilator going?" [Caregiver \#4]

This quote was related to the time frame of having visitors and was coded as: 1) unannounced visitors; 2) visitors are inappropriate while unconscious; and 3) visitors are appropriate / meaningful when conscious. Throughout the analysis process, specific events were coded and grouped together based on similarities, also known as categories (Strauss, 1987). Next, authors identified properties, which are detailed characteristics that pertain to a specific category, leading to identification of salient dimensions of family caregivers' experience (Strauss \& Corbin, 1998). 
Constant comparative analysis was used to compare participants' experiences and events (Strauss \& Corbin, 1998). Next, we used axial coding to look for similarities and variations in categories, subcategories, and properties, and determined how they related to one another (Strauss \& Corbin, 1998). For instance, after identifying that family caregivers focused on managing visitors, with the purpose of protecting the patient's safety, we used axial coding to dichotomize safety into two conceptually distinct subdimensions that were related to one another: physical safety and emotional safety. Conditions were identified, which provided context to the events family caregivers experienced (Corbin \& Strauss, 2008). Conditions that appeared frequently throughout our data related to the family caregiver's perception of visitors' threat to the patient's safety, specifically relating to threats to physical and emotional safety. Finally, authors used selective coding to confirm the core category and integrate all categories, resulting in a conceptual model (Strauss, 1987). A conceptual model is used to illustrate the relationships between salient categories that are grounded in the data (Charmaz, 2014). In our study, the core category was managing visitors, which was associated with two other categories: welcome visitors and unwelcome visitors. Data collection and analysis continued until saturation on selected categories (i.e., managing visitors) was reached, whereby it was determined that "the researcher cannot discover new dimensions in the data being collected" (Bowers, 1990, p. 48).

Consistent with Charmaz (2014), we used grounded theory evaluation criteria of credibility, originality, resonance, and usefulness to ensure rigor. We ensured credibility by selecting a core category and subcategories that covered the experience of multiple participants. In addition, we incorporated quotes from the majority of our participants to demonstrate sufficiently representative evidence of our findings (Charmaz, 2014). We achieved originality by electing to focus on a core category and subcategories that would offer new insights for healthcare providers on the process of managing visitors for family caregivers of patients with TBI during the hospital stay. We also achieved resonance by developing a conceptual model that represented the experience of our participants and was confirmed by participants through member checking (Charmaz, 2014). We used member checking to determine whether our participants' experiences were accurately described in our conceptual model. To do so, during data collection, the first author showed participants pieces of the conceptual model and asked for feedback on whether their experience was included, missing, or could be more accurately described. We used the participants' feedback to elaborate on and confirm our conceptual model (Charmaz, 2014). Finally, usefulness was achieved by ensuring our research included "interpretations that people can use in their everyday worlds" (Charmaz, 2014, p. 338).

In addition, ongoing memo writing increased the rigor of our study to: (a) reduce and limit introduction of bias or preconceived notions into development of our conceptual model; (b) generate information for data collection and analysis, including ideas for theoretical sampling, and (c) assist with development of the conceptual model, and interrelations among dimensions (Charmaz, 2014; Strauss \& Corbin, 1998). We referred back to our memos as needed throughout the study and we prepared our manuscript. 


\section{Results}

The core category in our findings was managing visitors (see Figure 1). Many family caregivers focused on managing visitors and there was considerable effort involved. Managing visitors was intended to: 1) protect the patient's safety and 2) to conserve family caregiver's own energy. Family caregivers were concerned about two types of safety for the patient: physical and emotional. Protecting the patient's physical safety focused on preventing re-injury, fatigue, or overstimulation; protecting the patient's emotional safety focused on stabilizing the patient's emotional state. Family caregivers attempted to conserve energy to have enough energy to focus on the patient.

\section{Managing Visitors}

Family caregivers characterized visitors in two ways: welcome or unwelcome. Welcome visitors included people who were believed to have a positive influence on the patient, the family caregiver, or both. Unwelcome visitors were people perceived to have a negative (or potentially negative) influence on the patient, the family caregiver, or both. Some visitors were initially welcome but were shifted to unwelcome based on visiting behavior.

Welcome visitors.-Welcome visitors were considered safe people. For instance, safe visitors: 1) did not (or had not) cause the patient any physical harm; 2) had a positive attitude or demeanor; 3) had a positive effect on the patient, such as making the patient smile and laugh. "Nobody was allowed in her room unless they had a happy face and a happy voice! Happy thoughts. Positive energy. This is what we try to keep going in her room.” [Caregiver $\# 1]$

Welcome visitors could also benefit the family caregiver by providing: 1) emotional support, 2) tangible support (such as bringing food or clothes), or 3) assistance with the family caregiver's hospital work. These visitors were often the family caregiver's family members and close friends.

"We have great group of friends. It may not help at the time for the patient, but what a difference for me. I wasn't even thinking about food. My friends brought in baskets of food, not for my husband, but for me. So that made a difference."

[Caregiver \#10]

\section{Managing welcome visitors.}

Approach \#1: Managing welcome visitors alone.: Most family caregivers were able to manage welcome visitors alone. Welcome visitors were often encouraged to visit throughout the hospital stay. Only the number and frequency of welcome visitors, as well as the timing and duration of their visits needed to be managed. This included sequencing visitors to avoid over-stimulating the patient and to allow the family caregiver to rest in between visitors in effort to conserve energy. Family caregivers also managed visitors as a group and individually before and after visitors arrived to the hospital.

Before welcome visitors arrive to the hospital.: When managing welcome visitors alone, family caregivers attempted to manage visitors as a group before they visited. Family 
caregivers who regularly used social media used Facebook to communicate with visitors. This involved posting daily status notifications to inform welcome visitors whether to visit that day, instructing them on frequency and duration of visits, and coordinating visits. "I had put messages out on Facebook saying that, 'Okay, well this is what her status is. And the rooms are small. We're not accepting visitors right now" [Caregiver \#3]. Those less familiar with social media used email or phone trees, contacting one or two people and having them pass the word on.

"We kind of had a phone tree. So, like I was assigned central contact and then I would pass it on to my dad. Then my dad would call my ex-husband and they'd kind of disperse information on to the rest of the family."

[Caregiver \#6]

There was a large volume of individual people contacting family caregivers via phone calls and text messages to determine when would be a good time to visit the patients. Family caregivers who did not feel overwhelmed responded to each call and text by sharing pertinent information about visiting. Those who felt overwhelmed chose not to respond or chose to direct welcome visitors to Facebook for more information. "My phone rang up so much that it actually shook itself off the table because it did not stop going off from all the calls and text messages. So, I started directing people to Facebook." [Caregiver \#7]

To manage potentially problematic people who were a possible threat to the patient's safety, family caregivers had conversations with them before they arrived and asked them not to overwhelm the patient or give them unpleasant information.

After welcome visitors arrive to the hospital.: Once welcome visitors arrived, family caregivers who were assertive asked them to limit the duration of their visit. When some family caregivers felt the visit was long enough or felt the patient was becoming overstimulated or fatigued, they asked the visitor to leave.

"And then if they didn't leave, I'd say, well, I think my husband looks like he's getting a little tired so we're going to go into the room and have him lie down. And so that was their cue to leave." [Caregiver \#8]

Consequences of welcome visitors.: Family caregivers often had success in managing welcome visitors. Family caregivers reported that the presence of these visitors often brought the patient back to reality.

"Yeah, he's had visitors, and I think it was real good. In fact, once he became aware of his surroundings again, I think that's when it would have been the most important because that was bringing him back to reality"

[Caregiver \#6].

However, managing welcome visitors was fatiguing. "It was exhausting for me because I basically had to play hostess for hours on end, and it was very difficult" [Caregiver \#9].

How managing welcome visitors changed over time.: Managing welcome visitors changed over time and the phase of the patient's recovery was also used in determining who 
was welcome at the following times: 1) early in recovery; and 2) later in recovery. Early in recovery, usually during critical care, family caregivers limited visitors to close family members and friends. "When he was first admitted, my husband and I asked that they just be immediate family coming to visit" [Caregiver \#12].

Later in the patient's recovery, often during inpatient rehabilitation, some family caregivers were less restrictive and allowed an increase in the frequency and duration of welcome visits.

"When he was in ICU, we never went more than two at a time. We would visit and just stay short amounts of time. As he got better, especially on rehab, the more he started to interact with us and the more awake times he had, that made a difference as to how long we would stay."

[Caregiver \#11]

However, regardless of phase of recovery, unwelcome visitors were prevented from visiting.

Unwelcome visitors.-Unwelcome visitors were considered dangerous people. Unwelcome visitors were defined as people whom family caregivers perceived to pose a threat to the patient's physical or emotional safety, people who would take away the family caregiver's own energy, or both. Unwelcome included people whom the family caregiver: 1) no longer wanted the patient to have a relationship with due to past and potentially future negative influence; 2) perceived would overstimulate the patient; 3 ) thought would tell the patient unpleasant information; 4) presumed would take away energy from the family caregiver by being a nuisance or being overly emotional. Unwelcome visitors were also people who arrived unannounced.

In addition to the above-listed considerations, to determine who was unwelcome, family caregivers often assessed the visitors' relationship to the patient, focusing on the visitor's level of closeness to the patient. Those who family caregivers perceived to not be close to the patient (e.g., those claiming to be friends of the patient who were unknown to the family caregiver) were unwelcome. To prevent any threats to the patient's physical and emotional safety, some family caregivers made a valiant effort to block unwelcome visitors from seeing the patient.

Three approaches to managing unwelcome visitors.-Family caregivers managed unwelcome visitors using three main approaches: 1) managing unwelcome visitors alone; 2) managing unwelcome visitors with others; and 3) managing unwelcome visitors by collaborating with staff (see Figure 1). Family caregivers used various combinations of all three approaches. Family caregivers managed visitors as a group, and individually before and after they arrived to the hospital.

Approach \#1: Managing unwelcome visitors alone.: Multiple family caregivers reported using approach \#1, managing unwelcome visitors alone, before and after visitors arrived to the hospital. 
Before unwelcome visitors arrive to the hospital.: Some family caregivers who managed unwelcome visitors alone also attempted to do so using Facebook. When a person unknown to the family caregiver inquired about visiting on Facebook, the family caregiver assessed the nature of the potential visitor's relationship to the patient and his or her motivation for wanting to visit.

"I told all of her friends that I already had on my Facebook friends list, 'Tell others if they want to visit, send me a Facebook message, say who you are, say why you want the information, and I will add you. Just so long as you can tell me who told you to talk to me and why you want to visit.'”

[Caregiver \#4]

People perceived to be a definite threat to the patient's emotional safety were kept at a distance. Family caregivers talked with these people directly and told them not to come, gave them permission to be away, and gave them work to do to keep them away.

"As far as he goes, it would have been difficult if he had dropped out of school and been sitting at her bedside this whole time. Honestly, I would have been trying to take care of him too, had he been here. I told him that his sister would want him to stay in school and to keep his grades up for her, and that way he didn't come."

[Caregiver \#1]

After unwelcome visitors arrive to the hospital.: Unwelcome visitors who arrived unannounced were often blocked from seeing the patient because family caregivers perceived unannounced visitors as dangerous, potentially threatening to the patient's safety.

"When [unwelcome] visitors showed up, I thanked them for coming and then asked them to leave. I was always very gracious, but I was very direct that my son was not up for visitors right now. I also asked them to call before coming in the future."

[Caregiver \#12]

Family caregivers who used Facebook to manage visitors often had to deal with visitors who did not use Facebook and arrived unannounced. Family caregivers' reactions to these visitors varied. Some family caregivers perceived these visitors had limited or no influence on the patient's safety and allowed them to see the patient. Family caregivers who perceived these visitors to have a negative influence on the patient's safety prevented them from seeing the patient and asked them to leave. Others expressed concerns about unwelcome visitors having a negative influence on the patient, but only hoped that these people would not continue to visit.

"If he was involved with any friends that were a negative influence in the past, it was kind of hard to let them come. Then I realized I'm just hoping that he's going to get past any of those thoughts of going backwards and just keep going forward."

[Caregiver \#5]

Overall, the strategies family caregivers implemented when managing visitors alone were not always successful. Success was determined by the ability to keep unwelcome visitors from coming to the hospital. When one strategy was not successful (such as using social 
media to communicate with visitors), family caregivers tried other strategies (such as asking unwelcome visitors to leave). Inability to manage unwelcome visitors caused family caregivers feelings of stress, anxiety, and being overwhelmed. Family caregivers reported limited involvement of staff in assisting them with managing unwelcome visitors, which led to frustration. "I was a little angry that they [staff] were letting other people aside from family just hanging, standing right next to the door of her room" [Caregiver \#3]. Because of this, family caregivers increased the time they spent at the hospital, or implemented other approaches, such as managing unwelcome visitors with others.

Approach \#2: Managing unwelcome visitors with others.: Some family caregivers reported managing unwelcome visitors with others, requesting assistance from family members or friends they trusted. Managing visitors with others often involved delegating at least some 'managing unwelcome visitors' tasks when the family caregiver was absent, when they were uncomfortable doing so, or when they felt overwhelmed.

Before unwelcome visitors arrive to the hospital.: Some family caregivers asked family members or friends to help update their Facebook when they became overwhelmed. Similar to strategies use to manage welcome visitors, family caregivers who were unfamiliar with Facebook had family members or friends communicate with unwelcome visitors using a phone or email tree.

"My cousin sent out mass emails to friends, family, and church group so people knew not to come. That extra person to help you relay other things to everybody else is super helpful because I can't do 50 emails or texts and phone calls per day."

[Caregiver \#12]

After unwelcome visitors arrived to the hospital.: When unwelcome visitors arrived at the hospital, family caregivers often had their family members and friends ask them to leave.

"He went to admissions and found out where she was. I found him sitting in front of her door. I ended up letting my friend deal with it. She looked at his face and said, "Now is not the time to be here." And she turned him around and walked him out."

[Caregiver \#3]

Family caregivers who managed unwelcome visitors with others were comfortable not being at the hospital constantly, as they could rely on others to help in their absence. "We're trying to stay, at least one of us, with him 24 hours. My husband does the nights and I do the days, because I'm not good at staying awake for long periods of time [chuckles]" [Caregiver \#13].

Consequences of managing unwelcome visitors using Approach \#1 and \#2.Family caregivers put a significant amount of energy and time into managing unwelcome visitors, which could have focused on the patient. These family caregivers also had lost productivity because they were constantly at the hospital instead of tending to other outside responsibilities. Family caregivers also reported feelings of stress, anxiety, frustration, and hypervigilance when managing unwelcome visitors without staff involvement. Lack of staff involvement caused family caregivers to feel exhausted and to distrust staff. 
Approach \#3: Managing unwelcome visitors by collaborating with staff.: [Note to author: Level 5 heading] Only four of family caregivers reported managing unwelcome visitors by collaborating with staff. Of these people, three had success in managing unwelcome visitors. There were also variations in who initiated the first conversation about visitors (initiated by staff or family caregiver).

Before unwelcome visitors arrived to the hospital.: One family caregiver reported initiating a conversation about visitors with staff immediately after the patient was admitted. This family caregiver was unsure if the patient's injury was intentional and perceived a severe threat to the patient's safety. The family caregiver asked staff to prevent anyone from receiving information about the patient and staff agreed to do so using a specific strategy: making the patient confidential. Staff had the family caregiver sign a form that listed the patient's room location as confidential in the patient registry. This strategy was successful and no unwelcome visitors came or were allowed to see the patient.

"At first I just wasn't allowing anybody to come. I went to talk to the staff and had them put her as confidential because we didn't know if somebody pushed her. Even her friends wanted come and see her in the hospital, but I wasn't allowing anyone."

[Caregiver \#1]

In a situation where a family caregiver was unable to successfully manage unwelcome visitors alone and with others, the family caregiver enlisted the help of staff by approaching staff about the ongoing issue. Staff suggested implementing a list of approved visitors. The family caregiver gave staff the list and asked for it to be enforced at all times. This strategy was not successful as the list of approved visitors was rarely enforced and unwelcome visitors were allowed access to the patient.

"I wish that was handled different and even when we gave them a family list, there were people coming still getting in to see her I thought had no business being there. They're obviously busy and it's too much to ask they help in keeping people out"

[Caregiver \#3]

In two other situations, staff approached two, separate family caregivers immediately after the patient was admitted to intensive care to discuss visitors, determining whether any visitors would be coming and assessing the family caregiver's concerns about visitors. After these family caregivers shared concerns about visitors, staff implemented strategies to prevent unwelcome visitors and communicated openly about their efforts. Staff asked the family caregivers to provide a list of approved visitors, and the family caregivers perceived staff would enforce this list in their absence.

"We gave them a list of approved visitors, it was my daughters, their spouses, and myself...No one really went against it, but the nurses did say, if somebody that wasn't on the list came, they would tell them the patient isn't taking visitors."

[Caregiver \#11]

Next, if any person was persistent in getting information about the patient over the phone, staff told the family caregiver and suggested making the patient confidential. 
"He did call and was extremely persistent about getting information. The nurse I talked to recommended that I sign this confidential form. She said without that form, he could call back, get my husband's room number, and come walking up there."

[Caregiver \#11]

After unwelcome visitors arrived to the hospital.: If a visitor came to see the patient, another strategy agreed upon was asking the family caregiver whether each visitor should be allowed to see the patient. However, this strategy required the family caregiver or another trusted person to be there at all times to determine who was welcome. "We had the staff ask us before they let anybody back there. The staff were instructed to ask us when each person arrived." [Caregiver \#13]. Finally, if the family caregiver had provided staff with a list of approved visitors, staff enforced this list, even in the family caregiver's absence.

Consequences of managing unwelcome visitors using Approach \#3.-Because of the actions of staff, almost all of these family caregivers perceived staff to be willing to assist in managing unwelcome visitors, particularly when staff implemented all agreed upon strategies. The family caregivers with this experience felt comfortable leaving the hospital to fulfill outside responsibilities, as they trusted that staff would manage visitors in their absence.

"I was very comfortable and that helped because I could not be there during the day. I knew he was in good hands. If somebody would have gotten past to visit that should not be there, I know the staff would've have asked them to leave."

[Caregiver \#11]

\section{Discussion}

The purpose of this study was to investigate family caregivers' experiences with visitors while patients with moderate-to-severe TBI are hospitalized. Results show family caregivers managed all visitors longitudinally during the hospital stay and put considerable effort into doing so. Family caregivers filtered welcome and unwelcome visitors and managed the number, frequency, duration, and timing of visits. Family caregivers reported limited success in managing unwelcome visitors and perceived staff were both unaware of their efforts and uninvolved in the process.

Research on hospital visitation policies during the hospital stay show that there are generic visitation policies during critical care, with restrictions that only limit the frequency and duration of visitors stays (Shulkin et al., 2014) as opposed to the visitor's characteristics and their perceived influence on the patient. As patients with moderate-to-severe TBI have cognitive impairments that may preclude them from stating their preferences on visitors, their family caregivers often make visiting decisions on their behalf. Thus, it is important to understand the process of family caregivers' management of visitors during the hospital stay so that staff may support family caregivers and determine opportunities for improving nursefamily collaboration. Yet, no research or clinical guidelines could be found to direct healthcare providers on assisting family caregivers with unwelcome visitors throughout the 
hospital stay. The generic nature of hospital visitation policies and clinical guidelines imply that there is a "one size fits all" visiting policy. This study shows that families are a lot more discriminating.

Family caregivers' use of protective caregiving strategies, often termed "family vigilance" (Carr, 2014), and attempts to conserve their own energy (Agard, Egerod, Tønnesen, \& Lomborg, 2015) during the hospital stay have been documented in the literature. However, current literature does not specify what the family is trying to protect the patient from or strategies they use to do this, which is demonstrated in this study. In addition, the literature suggests that family caregivers attempt to conserve energy using self-care strategies, such as resting at the patient's bedside and decreasing the length and frequency of their own visits (Agard et al., 2015; Östlund, Bäckström, Saveman, Lindh, \& Sundin, 2016). Our study adds to the literature on strategies family caregivers use to protect the patient and to conserve their own energy during the hospital stay. In addition, multiple studies show the effect of burden outside the hospital for family caregivers (Ajay, Kasthuri, Kiran, \& Malhotra, 2017; Dionne-Odom et al., 2016), but few studies address the burden inside the hospital for family caregivers who are involved in the patient's care. This study adds to the literature on potential causes of burden inside the hospital for family caregivers.

As nurse-family collaboration is essential to improving patient care and family caregivers' wellbeing throughout the hospital stay (Carlsson, Carlsson, Prenkert, \& Svantesson, 2016; Frampton et al., 2017), it is important to determine if there are discrepancies in nurses' and family caregivers' perceptions. No literature exists that assesses nurses' perceptions of visitors for patients with cognitive impairments. However, when comparing the literature on nurses' general perceptions of visitors who come to see patients with other health conditions to the findings of this study focusing on families' perceptions, it is clear that nurses' and families' perceptions differ.

Regarding nurses' perceptions, the research seems divided between studies suggesting that visitation has either a negative or positive influence. Studies of negative influence focus on the perceived effect of visitors on nurses and patients, identifying that some nurses perceive visitors make the environment unsafe by interfering with nurse roles/procedures (Nuss et al., 2014), increasing risk of infection for patients (Hart et al., 2013), and overstimulating the patient (Voncina \& Newcomb, 2016). Studies showing a positive influence identify visitors as valuable resource, particularly when family members assist in taking a patient history (Cappellini, Bambi, Lucchini, \& Milanesio, 2014) and provide the patient with emotional support (Segaric \& Hall, 2015; Voncina \& Newcomb, 2016). Based on literature and the current study, there appears to be overlap between nurses and family caregivers perceptions only concerning patient overstimulation (Voncina \& Newcomb, 2016). These discrepancies in perceptions of visitors can cause frustration and miscommunication between nurses and family caregivers, which may negatively affect nurse-family relationships. Our study adds to the literature by identifying potential areas of discrepancies, which can be addressed when supporting the family of the patient. 


\section{Implications for Practice}

These findings have implications for nurse-family collaboration to improve family nursing care, emphasizing the need for staff to have open communication with family caregivers about managing visitors (Bell, 2013; Frampton et al., 2017; Lor, Crooks, \& Tluczek, 2016). First, although this sample only included family caregivers of patients with moderate-tosevere TBI, these findings have wide reaching implications for family caregivers of patients hospitalized for various health conditions. Second, these findings can increase staff awareness that managing visitors is a difficult process for family caregivers during the hospital, particularly emphasizing the consequences of discrepancies in nurses' and families' perceptions about visitors. If nurses are only concerned that visitors will interfere with their work and pose an infection risk to the patient, they will likely miss family caregivers' concerns, leading unmet expectations and frustration. Nurses who would like to partner with family caregivers to potentially improve the care of the patient, improve the family caregiver's wellbeing, and decrease the family caregiver's in-hospital burden can inquire about family caregivers' visiting preferences to determine if there are any issues that need to be addressed.

Third, these findings not only raise questions for who should be responsible for managing unwelcome visitors, but have implications for system-level change to increase staff involvement in managing visitors. From a hospital administration standpoint, changing policies to state the institution should be held accountable to assist families to manage visitors may pose a liability; however it is still important to discuss ways staff can informally assist families. Recommendations for informal management of unwelcome visitors at the hospital-level include system change and administrative support to change visiting policies to address families' concerns by: 1) requiring each family to submit a list of approved visitors that is enforced by staff, 2) having all visitors check in at the nurses' station, and 3) giving the family caregiver visitors' badges to hand out to approved visitors and having staff ask people without badges to leave.

Fourth, it is important that staff are adequately trained and educated on how to assist family caregivers in this process. These findings can be used to educate healthcare providers, particularly nurses, to improve their understanding about the family's experience. Overall, family caregivers had difficulty managing unwelcome visitors alone or with others, suggesting healthcare providers need to use new or different strategies to support the wellbeing of family caregivers during the hospital stay, particularly as it relates to protecting the patient. In addition, recommendations for staff education and training include educating and training staff to: 1) talk with the family immediately after hospital admission and intermittently throughout the hospital stay to determine their needs about visitors and to notify them of limits that can be placed on visitors (e.g., a list of approved visitors); 2) be consistent with implementing family caregivers' requests about managing visitors (i.e., sharing requests at interdisciplinary team meetings and during hand-off); 3 ) educate family members on strategies to manage visitors, such as putting the blame on staff (e.g., "I'm sorry, my husband's nurse said he is not ready for visitors yet") or enlisting a trusted person indirectly involved with patient's care as gatekeeper (e.g., patient's aunt); and 4) tailor 
strategies for each family, as strategies that are useful for one family may not be useful for another (Jacob et al., 2016).

\section{Limitations}

First, this sample contains many family caregivers who had difficulty managing visitors, limiting knowledge about the strategies used by family caregivers who had success in managing visitors. However, as the majority of our sample had this experience, these findings may be representative of the typical experience for managing visitors. Second, all family caregivers in this sample were white, limiting application to family caregivers from diverse backgrounds. However, these findings provide a foundation for future research. Finally, the cause of each patient's injury was not taking into consideration, which may have altered strategies used. Regardless, without considering this factor, strategies used were consistent throughout our sample.

\section{Future Research}

The findings of this study describe the theoretical possibilities of managing visitors. More research is needed to determine the range, frequency, and distribution of family caregivers specific to managing visitors, including using a quantitative study to verify this conceptual model. As family caregivers seemed to have the most success managing visitors by collaborating with staff, researchers could further investigate this approach to managing visitors, including investigating staff's perceptions in managing visitors to better understand their perceived roles in this process. In addition, further research could be done to determine if staff assistance to family caregivers to manage visitors during the hospital stay has an effect on the wellbeing of the family caregiver. Other researchers may wish to simultaneously investigate nurses' and family caregivers' perceptions of visitors to determine if discrepancies exist. Finally, future researchers could investigate how managing visitors may vary for family caregivers from diverse backgrounds.

\section{Conclusion}

Family caregivers of patients with moderate-to-severe TBI play a large role in supporting the patient during the hospital stay, including managing visitors to protect the patient's physical and emotional safety and conserve their own energy. Our findings described the nuanced approaches used to protect patients during the hospital stay, showing positive and negative consequences to implementation of different approaches. Many family caregivers perceived staff to be unaware of their efforts to manage visitors and were uninvolved in this process. These findings provide evidence that management of visitors is an area where family caregivers need more assistance from hospital staff, showing that family caregivers are putting a significant amount of work into managing visitors, which could be affecting their wellbeing. An opportunity exists for nurses to collaborate with family caregivers to manage visitors by assessing family caregivers' visiting preferences and providing family caregivers with strategies to manage visitors. Doing so could improve family nursing care for patients with moderate-to-severe TBI. 


\section{Acknowledgements:}

Special thanks to dissertation committee members: Barbara Bowers, PhD, RN, FAAN (Chair); Lyn Turkstra, PhD, CCC-SLP; Barbara King, PhD, NP; Molly Carnes, MD, MS; Audrey Tluczek, PhD, RN; and David Maiers, PT. Thank you to university faculty and staff and staff at the participating recruitment locations.

Funding: This research was funded by the National Institute of Nursing Research (NINR) and the Eunice Kennedy Shriver National Institute of Child Health \& Human Development (NICHD) Grant \#F31NR015398 (PI, T. Oyesanya) and by the University of Wisconsin-Madison, School of Nursing Eckburg Research and Eckburg Dissertation Research Awards. This project was partially supported by the NIH/NIGMS Initiative for Maximizing Student Development (PI, M. Carnes) Grant\# R25GM083252 and the Clinical and Translational Science Award (CTSA) program, through the NIH National Center for Advancing Translational Sciences (NCATS), Grant\# UL1TR000427. The content is solely the responsibility of the authors and does not necessarily represent the official views of the NIH.

\section{Biographical Paragraphs}

Tolu Oyesanya, PhD, RN, is a Post-Doctoral Fellow in Brain Injury Research at Shepherd Center in Atlanta, Georgia, USA. Her dissertation research at the University of WisconsinMadison was funded by the National Institutes of Health and focused on the experience of the hospital stay for patients with traumatic brain injury (TBI) and their families. Her current research focuses on supporting patients with TBI and their families as they transition home from the hospital, with an emphasis on decreasing rehospitalizations after discharge. Recent publications include:

Oyesanya, T. O., \& Bowers, B. J. (in press). "I'm trying to be the safety net": Family protection of patients with moderate-to-severe TBI during the hospital stay. Qualitative Health Research.

Oyesanya, T. O. (2017). The experience of patients with ABI and their families during the hospital stay: A systematic review of qualitative literature. Brain Injury. Advance online publication. doi: 10.1080/02699052.2016.1225987

Oyesanya, T. O., Thomas, M. A., Brown, R. L, \& Turkstra, L. S. (2016). Nurses’ beliefs about caring for patients with traumatic brain injury. Western Journal of Nursing Research, 38(9), 1114-1138. doi: 10.1177/0193945916636629

Barbara Bowers, PhD, RN, FAAN, is the Charlotte J. and Ralph A. Rodefer Chair in Nursing and Associate Dean for Research at the School of Nursing, University of Wisconsin-Madison, USA. Her research interests focus on models of care for older adults and people with cognitive disabilities. She is an expert in the Grounded Theory research method. Recent publications include:

Webber, R., Bowers, B. J., \& Bigby, C. (2016). Confidence of group home staff in supporting the health needs of older residents with intellectual disability. Journal of Intellectual and Developmental Disability, 41(2), 107-114. doi :

10.3109/13668250.2015.1130218

Bowers, B. J., Roberts, T., Nolet, K., \& Ryther, B. (2016). Inside the Green House "black box": Opportunities for high-quality clinical decision making. Health Services Research, 51(S1), 378-397. doi: 10.1111/1475-6773.12427 
Roll, A. E., \& Bowers, B. J. (2016). Promoting healthy aging of individuals with developmental disabilities: A qualitative case study. Western Journal of Nursing Research. Advance online publication. doi:10.1177/0193945916668329

\section{References}

Agard AS, Egerod I, Tønnesen E, \& Lomborg K (2015). From spouse to caregiver and back: a grounded theory study of post-intensive care unit spousal caregiving. Journal of Advanced Nursing, 71(8), 1892-1903. [PubMed: 25827018]

Ajay S, Kasthuri A, Kiran P, \& Malhotra R (2017). Association of impairments of older persons with caregiver burden among family caregivers: Findings from rural South India. Archives of Gerontology and Geriatrics, 68, 143-148. https://doi.org/10.1016/j.archger.2016.10.003 [PubMed: 27810662]

American Speech-Language-Hearing Association. (2017). Traumatic brain injury (TBI). Retrieved January 17, 2017, from http://www.asha.org/public/speech/disorders/TBI/

Bell JM (2013). Family nursing is more than family centered care [Editorial]. Journal of Family Nursing, 19(4), 411-417. doi:10.1177/1074840713512750 [PubMed: 24227014]

Blumer H (1969). The methodological position of symbolic interactionism. Symbolic Interactionism: Perspective and Method, 1-60.

Bowers B (1990). Grounded theory In Sarter B (Ed.), Paths to knowledge. New York, NY: National League for Nursing Press.

Bowers B, \& Schatzman L (2009). Dimensional analysis. Developing Grounded Theory: The Second Generation, 86-126.

Cappellini E, Bambi S, Lucchini A, \& Milanesio E (2014). Open intensive care units: A global challenge for patients, relatives, and critical care teams. Dimensions of Critical Care Nursing, 33(4), 181-193. https://doi.org/10.1097/DCC.0000000000000052 [PubMed: 24895947]

Carlsson E, Carlsson AA, Prenkert M, \& Svantesson M (2016). Ways of understanding being a healthcare professional in the role of family member of a patient admitted to hospital. A phenomenographic study. International Journal of Nursing Studies, 53, 50-60. https://doi.org/ 10.1016/j.ijnurstu.2015.10.004 [PubMed: 26508538]

Carr JM (2014). A middle range theory of family vigilance. Medsurg Nursing, 23(4), 251. [PubMed: 25318339]

Centers for Disease Control and Prevention. (2014). Report to congress on traumatic brain injury in the United States: Epidemiology and Rehabilitation. Atlanta, GA: National Center for Injury Prevention and Control; Division of Unintentional Injury Prevention.

Centers for Disease Control and Prevention. (2016). TBI data and statistics. Retrieved from https:// www.cdc.gov/traumaticbraininjury/data/index.html

Chapman DK, Collingridge DS, Mitchell LA, Wright ES, Hopkins RO, Butler JM, \& Brown SM (2016). Satisfaction with elimination of all visitation restrictions in a mixed-profile intensive care unit. American Journal of Critical Care, 25(1), 46-50. https://doi.org/10.4037/ajcc2016789 [PubMed: 26724293]

Charmaz. (2014). Constructing grounded theory. Thousand Oaks, CA: Sage.

Clay A, \& Parsh B (2014). Patient-and family-centered care: Not just for kids. Nursing2015, 44(5), 57-58.

Corbin J, \& Strauss A (Eds.). (2008). Basics of qualitative research: Techniques and procedures for developing grounded theory. Sage Publications.

Corrigan JD, \& Hammond FM (2013). Traumatic brain injury as a chronic health condition. Archives of Physical Medicine and Rehabilitation, 94(6), 1199-1201. https://doi.org/10.1016/j.apmr. 2013.01.023 [PubMed: 23402722]

Creswell JW (2013). Research design: Qualitative, quantitative, and mixed methods approaches. Sage.

Despins EH, Turkstra LS, Struchen MA, \& Clark AN (2016). Sex-based differences in perceived pragmatic communication ability of adults with traumatic brain injury. Archives of Physical 
Medicine and Rehabilitation, 97(2), S26-S32. https://doi.org/10.1016/j.apmr.2014.06.023 [PubMed: 25662398]

Dionne-Odom JN, Hull JG, Martin MY, Lyons KD, Prescott AT, Tosteson T, ... Bakitas MA (2016). Associations between advanced cancer patients' survival and family caregiver presence and burden. Cancer Medicine. https://doi.org/10.1002/cam4.653

Failla MD, Juengst SB, Graham KM, Arenth PM, \& Wagner AK (2016). Effects of depression and antidepressant use on cognitive deficits and functional cognition following severe traumatic brain injury. Journal of Head Trauma Rehabilitation. https://doi.org/10.1097/HTR.0000000000000214

Frampton SB, Guastello S, Hoy L, Naylor M, Sheridan S, \& Johnstone-Fleece (2017). American Academy of Medicine. Discussion paper. Harnessing evidence and experience of change culture: A Guiding Framework for Patient and Family Engaged Care. Retrieved from https://nam.edu/ harnessing-evidence-and-experience-to-change-culture-a-guiding-framework-for-patient-andfamily-engaged-care/

Gagnon A, Lin J, \& Stergiou-Kita M (2016). Family members facilitating community re-integration and return to productivity following traumatic brain injury-motivations, roles and challenges. Disability and Rehabilitation, 38(5), 433-441. https://doi.org/10.3109/09638288.2015.1044035 [PubMed: 25974226]

Gorji MAH, Araghiyansc F, Jafari H, Gorgi AMH, \& Yazdani J (2014). Effect of auditory stimulation on traumatic coma duration in intensive care unit of Medical Sciences University of Mazandarn, Iran. Saudi Journal of Anaesthesia, 8(1), 69 https://doi.org/10.4103/1658-354X.125940 [PubMed: 24665243]

Hart A, Hardin SR, Townsend AP, Ramsey S, \& Mahrle-Henson A (2013). Critical care visitation: nurse and family preference. Dimensions of Critical Care Nursing, 32(6), 289-299. https://doi.org/ 10.1097/01.DCC.0000434515.58265.7d [PubMed: 24100430]

Jacob M, Horton C, Rance-Ashley S, Field T, Patterson R, Johnson C, ... Frobos C (2016). Needs of patients' family members in an intensive care unit with continuous visitation. American Journal of Critical Care, 25(2), 118-125. https://doi.org/10.4037/ajcc2016258 [PubMed: 26932913]

Kolakowsky-Hayner SA, Bellon K, \& Yang Y (2016). Unintentional injuries after TBI: Potential risk factors, impacts, and prevention. NeuroRehabilitation, 39(3), 363-370. https://doi.org/10.3233/ NRE-161368 [PubMed: 27497469]

Lor M, Crooks N, \& Tluczek A (2016). A proposed model of person-, family-, and culture-centered nursing care. Nursing Outlook, 64, 352-366. https://doi.org/10.1016/j.outlook.2016.02.006 [PubMed: 27061841]

Majdan M, Plancikova D, Brazinova A, Rusnak M, Nieboer D, Feigin V, \& Maas A (2016). Epidemiology of traumatic brain injuries in Europe: A cross-sectional analysis. The Lancet Public Health, 1(2), e76-e83. https://doi.org/10.1016/S2468-2667(16)30017-2 [PubMed: 29253420]

Nalder E, Fleming J, Cornwell P, \& Foster M (2012). Linked lives: The experiences of family caregivers during the transition from hospital to home following traumatic brain injury. Brain Impairment, 13(1), 108-122. https://doi.org/10.1017/BrImp.2012.4

Nuss T, Kelly KM, Campbell KR, Pierce C, Entzminger JK, Blair BK, ... Walker JL (2014). The impact of opening visitation access on patient and family experience. Journal of Nursing Administration, 44(7/8), 403-410. [PubMed: 25072230]

Östlund U, Bäckström B, Saveman B-I, Lindh V, \& Sundin K (2016). A Family Systems Nursing approach for families following a stroke: Family health conversations. Journal of Family Nursing, 22(2), 148-171. doi: 10.1177/1074840716642790 [PubMed: 27090511]

Oyesanya TO (2017). The experience of patients with ABI and their families during the hospital stay: A systematic review of qualitative literature. Brain Injury. Advance online publication https:// doi.org/10.1080/02699052.2016.1225987

Oyesanya T, \& Bowers BJ (in press). "I'm trying to be the safety net": Family protection of patients with moderate-to-severe TBI during the hospital stay. Qualitative Health Research.

Segaric CA, \& Hall WA (2015). Progressively engaging: constructing nurse, patient, and family relationships in acute care settings. Journal of Family Nursing, 21(1), 35-56. doi: 10.1177/1074840714564787 [PubMed: 25538050] 
Shulkin D, O'Keefe T, Visconi D, Robinson A, Rooke AS, \& Neigher W (2014). Eliminating visiting hour restrictions in hospitals. Journal for Healthcare Quality, 36(6), 54-57. https://doi.org/10.1111/ jhq. 12035

Steward KA, Gerstenecker A, Triebel KL, Kennedy R, Novack TA, Dreer LE, \& Marson DC (2016). Twelve-month recovery of medical decision-making capacity following traumatic brain injury. Neurology, 87(10), 1052-1059. [PubMed: 27511180]

Strauss A (1987). Qualitative analysis for social scientists. New York, NY: Cambridge University Press.

Strauss A, \& Corbin J (1998). Basics of qualitative research: Procedures and techniques for developing grounded theory. Thousand Oaks, CA: Sage Publications.

Togher L, McDonald S, Tate R, Rietdijk R, \& Power E (2016). The effectiveness of social communication partner training for adults with severe chronic TBI and their families using a measure of perceived communication ability. NeuroRehabilitation, (Preprint), 1-13. https:// doi.org/10.3233/NRE-151316

Turkstra LS (2013). Inpatient cognitive rehabilitation: Is it time for a change? The Journal of Head Trauma Rehabilitation, 28(4), 332-336. https://doi.org/10.1097/HTR.0b013e31828b4f3f [PubMed: 23535392]

Voncina G, \& Newcomb P (2016). Effects of enhanced family visitation in postanesthesia services. Journal of PeriAnesthesia Nursing. https://doi.org/10.1016/j.jopan.2014.12.004

Wu C, Melnikow J, Dinh T, Holmes JF, Gaona SD, Bottyan T, ... Nishijima DK (2015). Patient admission preferences and perceptions. Western Journal of Emergency Medicine, 16(5), 707 https://doi.org/10.5811/westjem.2015.7.27458 [PubMed: 26587095] 


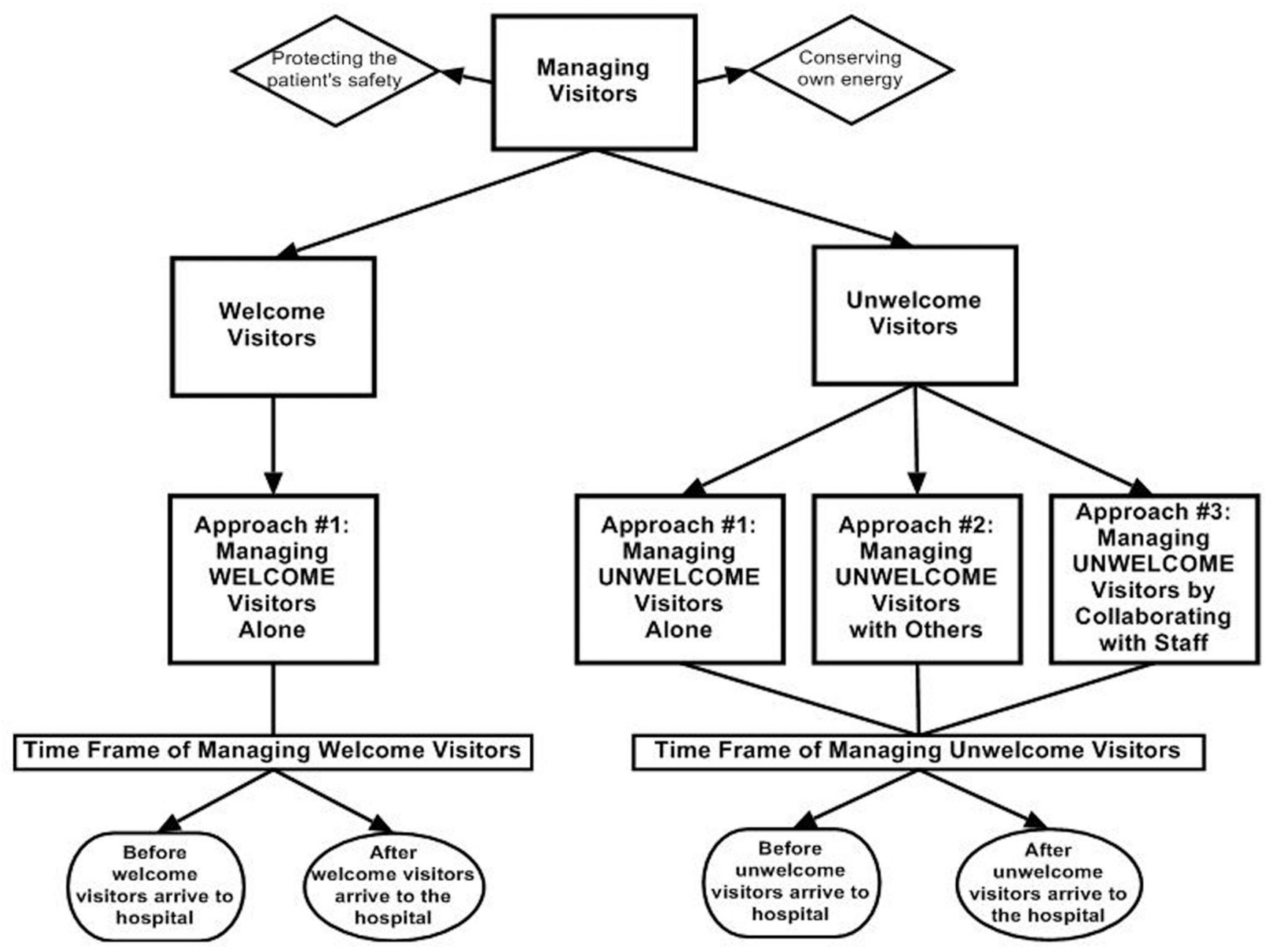

Figure 1.

Conceptual Model: Managing Visitors 